\title{
Review
}

\section{Cold Agglutinin Disease}

\author{
Amy P. Gabbard*, Garrett S. Booth \\ Department of Pathology, Microbiology, and Immunology, Vanderbilt University Medical Center, Nashville, TN, USA
}

\section{ARTICLE INFO}

\section{Article History}

Received 09 March 2020

Accepted 04 June 2020

\section{Keywords}

Hemolytic anemia

cold autoimmune hemolytic anemia cold agglutinins

cold agglutinin disease

cold agglutinin disease diagnosis

cold agglutinin disease therapy

\begin{abstract}
Cold agglutinin disease (CAD) is an uncommon form of cold autoimmune hemolytic anemia (AIHA). It should be considered in the differential diagnosis of elderly patients with unexplained chronic anemia presenting with or without cold-induced symptoms in the extremities, such as the fingers, ears, and nose. CAD is a complement-mediated process which leads to intravascular and extravascular hemolysis. A stepwise approach to laboratory testing can help confirm the diagnosis. Nearly all cold agglutinins are positive for the C3d direct antiglobulin test (DAT). A negative C3d DAT should prompt investigation of a possible warm AIHA. Ninety percent of cold agglutinins are of the IgM immunoglobulin class and should have a titer of 1:64 or higher at $4^{\circ} \mathrm{C}$. Distinction from a warm AIHA is important, as therapy differs for the two entities. Corticosteroids are not effective at treating CAD and should not be used as therapy in these patients. Approximately $45-60 \%$ of patients with CAD respond to rituximab monotherapy. Combination therapy of rituximab and fludarabine has been shown to be effective in up to $76 \%$ of patients; however, patients experience more mild side effects with this treatment. New anti-complement drugs, such as eculizumab and sutimlimab, are currently in phase- 3 trials to determine their efficacy and safety in patients with CAD.
\end{abstract}

(C) 2020 International Academy for Clinical Hematology. Publishing services by Atlantis Press International B.V. This is an open access article distributed under the CC BY-NC 4.0 license (http://creativecommons.org/licenses/by-nc/4.0/).

\section{INTRODUCTION}

Autoimmune hemolytic anemias (AIHAs) are clinicopathological entities characterized by the production of autoantibodies directed against surface antigens on red blood cells (RBCs) [1]. They are relatively uncommon, with an estimated incidence of $0.8-3$ per 100,000/year, prevalence of 17:100,000, and mortality of $11 \%$ in adults [2]. AIHAs are generally classified as warm, cold, or mixed type, depending on the optimum temperature at which the autoantibodies bind surface antigens. Warm and cold autoantibodies can be either idiopathic (primary) or due to an underlying condition (secondary) [3]. Cold AIHAs can be further characterized as primary chronic cold agglutinin disease (CAD), paroxysmal cold hemoglobinuria, or secondary cold AIHAs associated with an underlying condition, such as infection or malignancy (Table 1). CAD accounts for approximately $15-25 \%$ of AIHAs [3-5], with an incidence of 1 per million people/year [3]. Here, we review the clinical presentation, pathologic features, laboratory findings, and management of primary chronic CAD described in the literature.

\section{PATHOGENICITY}

The agglutination of blood at cold temperatures was discovered in the early 1900's by Landsteiner [6] and, soon thereafter, Clough and Richter [7] described the association of cold agglutinins and

"Corresponding author. Email: amy.p.gabbard@vumc.org

Peer review under responsibility of the International Academy for Clinical Hematology
$\mathrm{RBC}$ hemolysis and their occurrence with respiratory infections. These findings were supported by Horstmann and Tatlock [8], who reported the detection of cold agglutinins in the serum of a group of New England patients with primary atypical pneumonia. The term "cold agglutinin disease" was coined years later by Schubothe [9].

In general, cold agglutinins react at temperatures well below physiologic temperature, usually $0-4^{\circ} \mathrm{C}$, which may cause agglutination in the nose, ears, or fingers of patients, leading to painful coldinduced symptoms [1-3]. Approximately $90 \%$ of CAD patients have immunoglobulin $\mathrm{M}(\mathrm{IgM})$-mediated disease, while IgG and IgAmediated cases are rarely reported [3]. These cold agglutinins can be semi-quantitated in the lab with a titer based on their ability to agglutinate erythrocytes at $4^{\circ} \mathrm{C}$ [10]. Screening for cold agglutinins has shown that they are present in a high proportion of the adult population without any evidence of hemolysis or other underlying disease $[11,12]$. These incidental cold agglutinins are polyclonal and found in low titers, usually below 1:64 [12]. However, monoclonal cold agglutinins are likely to have higher titers and associated hemolysis, with the severity of disease dependent on a number of factors, including the degree of complement activation, the class and subclass of immunoglobulin, titer, specificity, and thermal amplitude of the cold agglutinin [10]. Diagnostic laboratory testing of a thermal amplitude refers to the highest temperature at which the cold agglutinins will react with the antigen [10]. While cold agglutinins react optimally at $4^{\circ} \mathrm{C}$, they may have a broader thermal amplitude with reactivity that extends closer to or up to physiologic temperature. These cold agglutinins are more likely to cause symptoms in patients and be clinically significant. 
Table 1 Secondary causes of cold AIHAs $[4,10]$

\begin{tabular}{ll}
\hline Infection & Malignancy \\
\hline Viral & Lymphoplasmacytic lymphoma \\
Epstein Barr virus (EBV) & Marginal zone lymphoma \\
Hepatitis B and C & Waldenström macroglobulinemia \\
Cytomegalovirus (CMV) & Aggressive non-Hodgkin lymphoma (NHL) \\
Adenovirus & \\
Influenza A & \\
Bacterial & \\
Mycoplasma pneumoniae & \\
Legionella pneumophilica & \\
Chlamydia pneumonia & \\
Listeriosis & \\
E. coli lung infection & \\
\hline
\end{tabular}

AIHAs, autoimmune hemolytic anemias.

The hemolysis in CAD is complement-mediated and can be intravascular or extravascular. Complement activation has been shown to occur in two steps, one of which is temperature dependent [13]. As blood circulates through the extremities and cooler skin, which can be as cool as $28-30^{\circ} \mathrm{C}$, cold agglutinins transiently bind the erythrocyte surface. As the erythrocytes with the bound Ig-C1 complex circulate back to warmer areas of the body, C1q esterase activates C4 and C2, which generates the C3 convertase. This step is temperature-dependent, as $\mathrm{C} 4$ requires higher temperatures to be enzymatically active [13]. C3 convertase cleaves C3 into C3a and $\mathrm{C} 3 \mathrm{~b}$. Erythrocytes coated with $\mathrm{C} 3 \mathrm{~b}$ are sequestered by macrophages in the reticuloendothelial system, particularly Kupffer's cells in the liver. Sequestration ultimately leads to destruction of these cells and extravascular hemolysis [14]. However, C3b can be further cleaved into $\mathrm{C} 3 \mathrm{c}$ and $\mathrm{C} 3 \mathrm{~d}$. C3d is found in large quantities on the surface of erythrocytes in patients with CAD, occupying potential binding sites for $\mathrm{C} 4$ and $\mathrm{C} 3$, preventing hemolysis of the patient's own cells. Transfused cells, however, are not coated by C3d and are susceptible to complement activation and hemolysis. If complement activation goes past the C3 step, the membrane attack complex with C5b-C9 may form, leading to intravascular hemolysis [14].

The efficiency of complement activation is dependent on the immunoglobulin isotype of the cold agglutinin. IgM is pentameric requiring only a single antibody to fix one $\mathrm{C} 1$ molecule and initiate the classical complement pathway, making it the most efficient $[13,15]$. IgG, on the other hand, is a smaller molecule, requiring more cold agglutinins to bind in order to activate complement [15]. The specific subclass of IgG is also important, as IgG3 and IgG1 fix complement much more efficiently than IgG2 and IgG4 [14]. Despite the overwhelming evidence in the literature that cold agglutinins of the IgM isotype with a broad thermal amplitude and high titer are likely to cause hemolysis, there are rare reports of cases contradicting this [16].

\section{DIAGNOSTIC TESTING}

\subsection{Clinical Manifestations}

Primary CAD should be considered in elderly patients with unexplained chronic anemia with or without associated cold-induced symptoms. Swiecicki et al. [3] reported a median age at presentation of 65 years of age in a population-based study of 89 patients from the United States. The most common presenting symptom was acrocyanosis, which is a dark purple to gray discoloration of the skin upon exposure to the cold in the acral areas, such as the fingertips, toes, nose, and ears, was found in $44 \%$ of patients. Other coldinduced symptoms, such as Raynaud phenomenon, were reported in another $39 \%$ of patients [3]. A second population-based study in Norway examined 86 patients demonstrating a median age at presentation of 67 years with yet more severe cold-induced circulatory symptoms (90\%) [17]. The higher percentage of patients experiencing cold-induced symptoms in the Norwegian population may be explained by the colder climate in Norway in comparison to that in the United States. These symptoms may wax and wane throughout a patient's course of disease. However, in rare cases, progression of acrocyanosis to skin necrosis has been reported [18].

\subsection{Laboratory Findings}

Laboratory findings can help to support the clinical suspicion of CAD. A complete blood count (CBC) typically demonstrates lowgrade anemia with or without an increased mean corpuscular volume and decreased RBC count [1]. Swiecicki et al. [3] reported a median hemoglobin of $10.2 \mathrm{~g} / \mathrm{dL}$ in the US population, while in Berentsen et al.s [17] series, the mean hemoglobin level was $9.2 \mathrm{~g} / \mathrm{dL}$. Elevated reticulocyte numbers, which indicate a functioning bone marrow, may also be seen as the marrow attempts to replace the lost RBCs [1]. Additional laboratory parameters, such as increased bilirubin levels and lactate dehydrogenase and decreased haptoglobin levels, usually support a picture of underlying hemolysis (Table 2) $[1,3,17]$.

\subsection{Laboratory Testing for Diagnosis}

There are multiple definitions in the literature as to what is required to make the diagnosis of CAD (Table 3). Regardless of the specific criteria used, if CAD is clinically suspected in a patient with unexplained anemia and hemolysis, the approach to further laboratory testing should be stepwise (Figure 1). It is important to note that the sample used for cold agglutinin testing should be kept at $37-38^{\circ} \mathrm{C}$ after collection until the serum is separated from the clot. The first test to perform is the polyspecific direct antiglobulin test (DAT). If this is positive, a monospecific DAT for C3d and IgG should be done. A negative anti-C3d DAT is unlikely to be seen in CAD. In these cases, a warm AIHA should be considered [10]. However, up to $22 \%$ of CAD cases may have a positive anti-IgG DAT, in addition to a positive anti-C3d DAT $[10,19]$. A positive anti-C3d should be followed

Table 2 Laboratory findings in cold agglutinin disease

\begin{tabular}{ll}
\hline Hemolysis labs & Cold-agglutinin specific labs \\
\hline Decreased hemoglobin & Polyspecific DAT positive \\
Increased bilirubin & C3d DAT positive \\
Increased LDH & Cold agglutinin titer $\geq 64$ at $4^{\circ} \mathrm{C}$ \\
Decreased haptoglobin & \\
\hline
\end{tabular}

LDH, lactate dehydrogenase; DAT, direct antiglobulin test. 
up with a cold agglutinin titer. A titer of 1:64 or more is required for diagnosis [13]. If the cold agglutinin titer does not reach this threshold, then again, a warm AIHA should be considered, as up to $67 \%$ of these can be positive for both anti-IgG DAT alone or anti-IgG and anti-C3d DAT [20,22,23].

Determining the immunoglobulin class is not required for diagnosis, but may be useful in further classification of an autoantibody with broad thermal amplitude. Up to $90 \%$ of cold agglutinins are monoclonal IgM class immunoglobulins, while $<7 \%$ of cases are monoclonal IgA and IgG class antibodies combined $[3,17]$. Regardless of immunoglobulin class, cold agglutinins usually have kappa light chain restriction, with reports ranging from $94 \%$ to $100 \%[17,21]$. The immunoglobulin class and light chain restriction may help to classify autoantibodies that are difficult to distinguish from warm autoantibodies, as warm autoantibodies are generally IgG isotype and are less likely to be IgM or IgA [22].

Table 3 Diagnostic criteria for cold agglutinin disease

\begin{tabular}{|c|c|}
\hline Publication & Criteria \\
\hline $\begin{array}{l}\text { Berentsen et al., } 2012 \\
\text { [11] }\end{array}$ & $\begin{array}{l}\text { (1) Chronic hemolysis } \\
\text { (2) Positive polyspecific DAT } \\
\text { (3) Strongly positive monospecific C3d DAT } \\
\text { (4) Cold agglutinin titer } \geq 64 \text { at } 4^{\circ} \mathrm{C}\end{array}$ \\
\hline $\begin{array}{l}\text { Barcellini et al., } 2014 \\
\text { [19] }\end{array}$ & $\begin{array}{l}\text { (1) Hemolytic anemia } \\
\text { (2) Positive DAT for C } 3 \mathrm{~d} \text { only } \\
\text { (3) Cold agglutinin titer } \geq 64 \text { at } 4^{\circ} \mathrm{C} \\
\text { (4) Cold agglutinin with I specificity }\end{array}$ \\
\hline Petz, 2004 [20] & $\begin{array}{l}\text { (1) Acquired hemolytic anemia } \\
\text { (2) Positive C3 DAT } \\
\text { (3) Negative IgG DAT } \\
\text { (4) Cold autoagglutination with reactivity up } \\
\text { to at least } 30^{\circ} \mathrm{C} \text { in saline or albumin } \\
\text { (5) Cold agglutinin titer } \geq 256 \text { at } 4^{\circ} \mathrm{C}\end{array}$ \\
\hline
\end{tabular}

Similar to warm autoantibodies, cold agglutinins tend to have specificity for certain non-ABO blood group antigens. Approximately $90 \%$ of cold agglutinins have anti-I specificity, while the remaining usually have anti-i specificity $[1,3,12]$. Neonatal RBCs can be used to demonstrate this specificity in the lab, as they exclusively express the $\mathrm{i}$ antigen. In contrast, the I antigen is found on $>99 \%$ of adult RBCs. Though most defining criteria of CAD do not require that anti-I/anti-i specificity be present, one group of authors [19] does include it as a criterion for diagnosis. Clinically, anti-I antibodies may be associated with Mycoplasma pneumoniae infections [24], while anti-i antibodies may be associated with Epstein-Barr virus mononucleosis [25].

\section{THERAPY}

\subsection{Non-pharmacological Treatment}

Since cold agglutinins bind in colder temperatures, patients are generally counseled to keep warm, particularly their head, face, and extremities. This has been shown to alleviate symptoms and may prevent severe exacerbations of hemolytic anemia. These findings are, however, of low-quality evidence. Recommendations are based on the clinical experience of authors, but the efficacy of these strategies have not been examined in trials $[3,10]$. Practically, it is unreasonable to expect a patient to constantly remain warm, and especially in winter months.

Symptomatic anemia can be treated with RBC transfusion. Blood bank testing for underlying alloantibodies and crossmatch testing should be performed at $37^{\circ} \mathrm{C}$ [26]. It is important to note, though, that cold agglutinins can cause interference with laboratory testing, such as ABO blood typing results and hematocrit levels in a CBC [27]. Furthermore, if the cold agglutinin has a broad thermal amplitude, obtaining crossmatch compatible blood may be a clinical challenge. Any interference with laboratory testing has the potential to

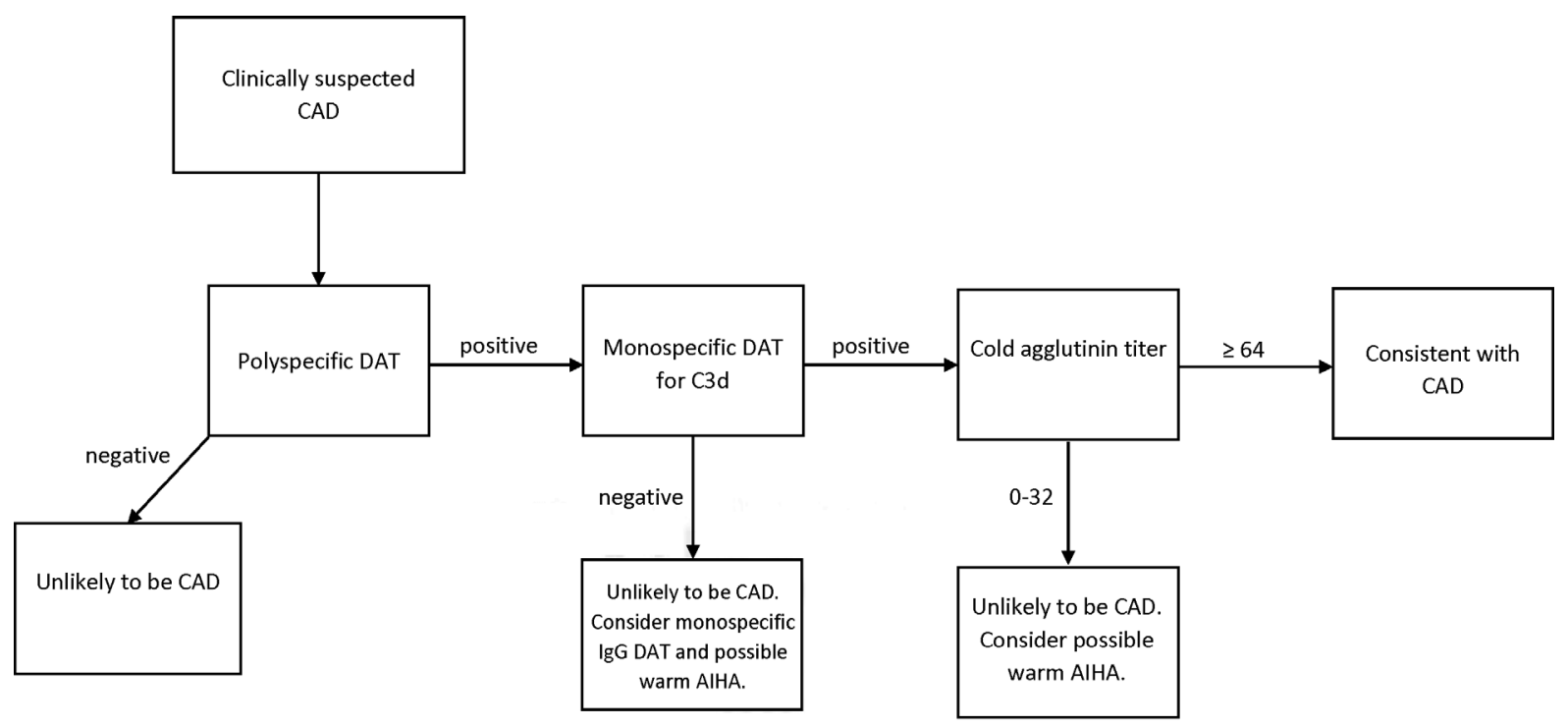

Figure $1 \mid$ Lab workup for suspected cold agglutinin disease. CAD, cold agglutinin disease; DAT, direct antiglobulin test; AIHA, auto immune hemolytic anemia. 
lead to delay in treatment, which has the potential for clinical harm to the patient. It is recommended that the patient be kept warm and an in-line blood warmer be used to prevent cold agglutinins from clotting and causing occlusions during transfusion [26,28-30].

Surgical intervention, including splenectomy, has been shown to be effective only in patients with IgG-mediated CAD, which represents only approximately $3.5 \%$ of patients [32]. Additionally, plasmapheresis has been undertaken as a temporary measure to remove IgM autoantibodies, but treatment with plasmapheresis has a narrow therapeutic window; it was shown to be effective in acute situations and before surgery requiring hypothermia $[28,31]$.

\subsection{Pharmacological Treatment}

Despite the importance of cold avoidance, approximately $70 \%$ of patients require pharmacological treatment [32]. The most common reason for treatment is chronic anemia $[3,32]$. Patients are generally started on corticosteroids, though the benefit of this practice has not been supported by the literature. Although corticosteroids are a rapid and effective treatment for warm AIHAs, they have not been shown to be as effective in CAD [31]. A few case studies reported that corticosteroids were most effective in patients with low-titer cold agglutinins, while those with high titers showed a poor response [33]. Retrospective studies have found that $<15 \%$ of patients respond to corticosteroids, and they require higher doses to maintain remission [17]. Due to the lack of response seen with corticosteroids, many authors recommend they are not used for the treatment of CAD $[11,34]$.

Rituximab, a monoclonal antibody directed against CD20, has been used to treat CAD since the late 1990s [10]. Two prospective, uncontrolled trials looked at its effectiveness at a weekly dose of $375 \mathrm{mg} / \mathrm{m}^{2}$ for 4 weeks $[35,36]$. Response rates were classified as complete response (CR), partial response (PR), or no response (NR) based on the criteria summarized in Table 4. Berentsen et al. [35] reported a CR or PR in $60 \%$ of patients, with a median hemoglobin increase of $4 \mathrm{~g} / \mathrm{dL}$. The median time to response was 1.5 months, and the median duration of treatment was 11 months [35]. In a similar study, Schöllkopf et al. found that $45 \%$ of patients either completely or partially responded to monotherapy with rituximab, with a median time to response of 3 months. The treatment was well tolerated by patients in both studies, with no severe infusion-related adverse effects [35,36].

Table $4 \mid$ Response criteria to therapy

\begin{tabular}{ll}
\hline Response level & Criteria \\
\hline $\begin{array}{l}\text { Complete } \\
\text { response }\end{array}$ & $\begin{array}{l}\text { (1) Absence of anemia } \\
\text { (CR) }\end{array}$ \\
& $\begin{array}{l}\text { (3) No clinns of hemolysis } \\
\text { (4) No monoclonal serum protein } \\
\text { (5) No evidence of lymphoproliferation on bone marrow }\end{array}$ \\
Partial response & $\begin{array}{l}\text { (1) Stable increase in hemoglobin by at least } 2.0 \mathrm{~g} / \mathrm{dL} \\
\text { or to normal range }\end{array}$ \\
& $\begin{array}{l}\text { (2) Reduction in serum IgM levels by at least } 50 \% \text { of } \\
\text { the initial level or to normal range }\end{array}$ \\
& (3) Improvement of clinical symptoms \\
& (4) Transfusion independence
\end{tabular}

No response (NR) Any outcome not meeting criteria for CR or PR
Though monotherapy with rituximab has been relatively successful, some studies have examined the effectiveness of combining a second drug, such as fludarabine, to increase the efficacy of treatment. Fludarabine is a purine nucleoside analog, which has shown to induce remission in at least two patients with CAD [10]. A prospective, uncontrolled study showed a $76 \%$ response rate to the combination therapy, $20 \%$ of which were CR [32]. Of the 22 patients who responded, 10 had been unresponsive to rituximab monotherapy. The overall median increase in hemoglobin was 3.1 $\mathrm{g} / \mathrm{dL}$, and the median time to response was 4 months. Despite the higher response rates with the combination therapy, a higher level of toxicity was seen, in comparison to rituximab monotherapy. Infection was the most common side effect, seen in $57 \%$ of patients, followed by neutropenia in $41 \%$ (Table 5) [32].

Berentsen et al. $[32,35]$ defined relapse as a decrease in the hemoglobin level to $10 \mathrm{~g} / \mathrm{dL}$ or by at least $2 \mathrm{~g} / \mathrm{dL}$ from the highest level achieved, and/or recurrence of clinical symptoms in the monotherapy and combination studies. With rituximab monotherapy, $60 \%$ of patients who had responded relapsed during the study, compared to $23 \%$ of patients who had responded with fludarabine-rituximab combination therapy. In both studies, all patients who relapsed were partial responders $[32,35]$.

\subsection{Future Therapies}

Since hemolysis in CAD is complement-mediated, the effect of complement system-targeting therapies has been investigated for the treatment of CAD. A prospective, non-randomized International multi-center study Demonstrating the Efficacy of Terminal Complement Inhibition in Patients with Cold Agglutinin Disease Using Eculizumab (DECADE) [37]. Eculizumab is an anti-C5 monoclonal antibody used to treat paroxysmal nocturnal hemoglobinuria. Patients in the study were treated with $600 \mathrm{mg}$ eculizumab weekly for 4 weeks, followed by $900 \mathrm{mg}$ every other week through week 26 . The primary endpoint was the difference in lactate dehydrogenase (LDH) at the beginning and end of therapy. The median LDH decreased from 572 to $334 \mathrm{U} / \mathrm{L}$, with $54 \%$ of the patients showing a decrease $\geq 250 \mathrm{U} / \mathrm{L}$. Patients with cold agglutinins with broad thermal amplitudes showed less response than patients with cold agglutinins with narrower thermal amplitudes. Eculizumab was well-tolerated, and the authors suggest that patients with broad thermal amplitude cold agglutinins may be treated with higher doses for better response. Despite its effect on decreasing hemolysis, eculizumab did not improve cold-associated symptoms, such as Raynaud syndrome [37]. Rare case reports support the findings of the DECADE trial, as well as the use of

Table 5 Pharmacological treatment options for cold agglutinin disease

\begin{tabular}{|c|c|c|}
\hline Treatment & Dose & $\begin{array}{l}\text { Response } \\
\text { rates }\end{array}$ \\
\hline Rituximab & $375 \mathrm{mg} / \mathrm{m}^{2}$ weekly for 4 weeks & $45-60 \%$ \\
\hline $\begin{array}{l}\text { Rituximab + } \\
\text { fludarabine }\end{array}$ & $\begin{array}{l}\text { Rituximab: } 375 \mathrm{mg} / \mathrm{m}^{2} \text { on days } 1,29 \text {, } \\
57 \text {, and } 85 \\
\text { Fludarabine: } 40 \mathrm{mg} / \mathrm{m}^{2} \text { on days } 1-5 \text {, } \\
29-34,57-61 \text {, and } 85-89\end{array}$ & $76 \%$ \\
\hline Eculizumab & $\begin{array}{l}600 \mathrm{mg} \text { weekly for } 4 \text { weeks; followed by } \\
900 \mathrm{mg} \text { every other week through week } 26\end{array}$ & $54 \%$ \\
\hline Sutimlimab & $\begin{array}{l}\text { To be determined - phase } 3 \text { clinical trial } \\
\text { in progress }\end{array}$ & $\begin{array}{l}\text { To be } \\
\text { determined }\end{array}$ \\
\hline
\end{tabular}


eculizumab in treating acute hemolysis in patients with chronic $\mathrm{CAD}$ and in decreasing hemolysis during surgery for chronic CAD patients [38-40].

A second complement system-targeting monoclonal antibody, sutimlimab (BIVV009), is currently under investigation. Sutimlimab is a humanized monoclonal antibody that inhibits the serine protease $\mathrm{C} 1 \mathrm{~s}$ in the classical complement pathway [41]. The mouse variant of sutimlimab, TNT003, has been shown to inhibit complement-dependent phagocytosis and lysis of RBCs induced by CAD patient autoantibodies $[42,43]$. Trials to determine the efficacy and safety of sutimlimab in patients with primary CAD, as well as other complement-mediated diseases, are currently in progress.

\section{CONFLICTS OF INTEREST}

The authors declare they have no conflicts of interest.

\section{AUTHORS' CONTRIBUTION}

AG wrote the manuscript and created the tables and figures and $\mathrm{GB}$ edited the manuscript. Both authors reviewed and approved the final manuscript.

\section{FUNDING}

The authors received no financial support for the authorship or publication of this article.

\section{REFERENCES}

[1] Gehrs BC, Friedberg RC. Autoimmune hemolytic anemia. Am J Hematol 2002;69;258-71.

[2] Zanella A, Barcellini W. Treatment of autoimmune hemolytic anemias. Haematologica 2014;99;1547-54.

[3] Swiecicki PL, Hegerova LT, Gertz MA. Cold agglutinin disease. Blood 2013;122;1114-21.

[4] Berentsen S. Cold agglutinin disease. Hematology Am Soc Hematol Educ Program 2016;2016;226-31.

[5] Berentsen S, Röth A, Randen U, Jilma B, Tjønnfjord GE. Cold agglutinin disease: current challenges and future prospects. J Blood Med 2019;10;93-103.

[6] Landsteiner K. Über Beziehungen zwischen dem Blutserum und den Körperzellen. Münch med Wschr 1903;50;1812-4.

[7] Clough MC, Richter IM. A study of an auto-agglutinin occurring in a human serum. Johns Hopkins Hosp Bull 1918;29;86-93.

[8] Horstmann DM, Tatlock H. Cold agglutinins: a diagnostic aid in certain types of primary atypical pneumonia. JAMA 1943;122;369-70.

[9] Schubothe H. The cold hemagglutinin disease. Semin Hematol 1966;3;27-47.

[10] Petz LD. Cold antibody autoimmune hemolytic anemias. Blood Rev 2008;22;1-15.

[11] Berentsen S, Tjønnfjord GE. Diagnosis and treatment of cold agglutinin mediated autoimmune hemolytic anemia. Blood Rev 2012;26;107-15.
[12] Gertz MA. Management of cold haemolytic syndrome. Br J Haematol 2007;138;422-9.

[13] Dacie J. Auto-immune haemolytic anaemia (AIHA): coldantibody syndromes II: immunochemistry and specificity of the antibodies; serum complement in autoimmune haemolytic anaemia. In: Dacie J, editor. The Haemolytic Anaemias, Vol 3. London: Churchill Livingstone; 1992, pp. 240-95.

[14] Kirschfink M, Knoblauch K, Roelcke D. Activation of complement by cold agglutinins. Infusionsther Transfusionsmed 1994;21;405-9.

[15] Zilow G, Kirschfink M, Roelcke D. Red cell destruction in cold agglutinin disease. Infusionsther Transfusionsmed 1994;21; $410-15$.

[16] Sniecinski I, Margolin K, Shulman I, Oien L, Meyer E, Branch DR. High-titer, high-thermal-amplitude cold autoagglutinin not associated with hemolytic anemia. Vox Sang 1988;55;26-9.

[17] Berentsen S, Ulvestad E, Langholm R, Beiske K, Hjorth-Hansen H, Ghanima W, et al. Primary chronic cold agglutinin disease: a population based clinical study of 86 patients. Haematologica 2006;91;460-6.

[18] Gregory GP, Farrell A, Brown S. Cold agglutinin disease complicated by acrocyanosis and necrosis. Ann Hematol 2017;96;509-10.

[19] Barcellini W, Fattizzo B, Zaninoni A, Radice T, Nichele I, Di Bona E, et al. Clinical heterogeneity and predictors of outcome in primary autoimmune hemolytic anemia: a GIMEMA study of 308 patients. Blood 2014;124;2930-6.

[20] Petz LD. Review: evaluation of patients with immune hemolysis. Immunohematology 2004;20;167-76.

[21] Chandesris MO, Schleinitz N, Ferrera V, Bernit E, Mazodier K, Gayet S, et al. Cold agglutinins, clinical presentation and significance: retrospective analysis of 58 patients. Rev Med Interne 2004;25;856-65.

[22] Kalfa TA. Warm antibody autoimmune hemolytic anemia Hematology Am Soc Hematol Educ Program 2016;2016;690-7.

[23] Michel M. Classification and therapeutic approaches in autoimmune hemolytic anemia: an update. Expert Rev Hematol 2011;4;607-18.

[24] Feizi T, Taylor-Robinson D. Cold agglutinin anti-I and Mycoplasma pneumoniae. Immunology 1967;13;405-9.

[25] Rosenfield RE, Schmidt PJ, Calvo RC, McGinniss MH. Anti-i, a frequent cold agglutinin in infectious mononucleosis. Vox Sang $1965 ; 10 ; 631-4$.

[26] Berentsen S. How I manage cold agglutinin disease. Br J Haematol 2011;153;309-17.

[27] Ercan Ş, Calışkan M, Koptur E. 70-year old female patient with mismatch between hematocrit and hemoglobin values: the effects of cold agglutinin on complete blood count. Biochem Med (Zagreb) 2014;24;391-5.

[28] Hill QA, Stamps R, Massey E, Grainger JD, Provan D, Hill A. The diagnosis and management of primary autoimmune haemolytic anaemia. Br J Haematol 2017;176;395-411.

[29] Rosenfield RE, Jagathambal. Transfusion therapy for autoimmune hemolytic anemia. Semin Hematol 1976;13;311-21.

[30] George MR, Herman JH. Transfusion medicine illustrated: transfusion interference by cold agglutinins. Transfusion 2013;53;3036.

[31] Silberstein LE, Berkman EM, Schreiber AD. Cold hemagglutinin disease associated with IgG cold-reactive antibody. Ann Intern Med 1987;106;238-42. 
[32] Berentsen S, Randen U, Vågan AM, Hjorth-Hansen H, Vik A, Dalgaard J, et al. High response rate and durable remissions following fludarabine and rituximab combination therapy for chronic cold agglutinin disease. Blood 2010;116; $3180-4$.

[33] Nanan R, Scheurlen W, Gerlich M, Huppertz HI. Severe low-titer cold-hemagglutinin disease responsive to steroid pulse therapy. Ann Hematol 1995;71;101-2.

[34] Dacie J. Treatment and prognosis of cold-antibody AIHA. In: Dacie J, editor. The Haemolytic Anaemias. Vol. 3. London: Churchill Livingstone; 1992, pp. 502-8.

[35] Berentsen S, Ulvestad E, Gjertsen BT, Hjorth-Hansen H, Langholm R, Knutsen H, et al. Rituximab for primary chronic cold agglutinin disease: a prospective study of 37 courses of therapy in 27 patients. Blood 2004;103;2925-8.

[36] Schöllkopf C, Kjeldsen L, Bjerrum OW, Mourits-Andersen HT, Nielsen JL, Christensen BE, et al. Rituximab in chronic cold agglutinin disease: a prospective study of 20 patients. Leuk Lymphoma 2006;47;253-60.

[37] Röth A, Bommer M, Hüttmann A, Herich-Terhürne D, Kuklik $\mathrm{N}$, Rekowski J, et al. Eculizumab in cold agglutinin disease (DECADE): an open-label, prospective, bicentric, nonrandomized phase 2 trial. Blood Adv 2018;2;2543-9.
[38] Makishima K, Obara N, Ishitsuka K, Sukegawa S, Suma S, Kiyoki Y, et al. High efficacy of eculizumab treatment for fulminant hemolytic anemia in primary cold agglutinin disease. Ann Hematol 2019;98;1031-2.

[39] Tjønnfjord E, Vengen ØA, Berentsen S, Tjønnfjord GE. Prophylactic use of eculizumab during surgery in chronic cold agglutinin disease. BMJ Case Rep 2017;2017;bcr2016219066.

[40] Gupta N, Wang ES. Long-term response of refractory primary cold agglutinin disease to eculizumab therapy. Ann Hematol 2014;93;343-4.

[41] Nikitin PA, Rose EL, Byun TS, Parry GC, Panicker S. C1s inhibition by BIVV009 (sutimlimab) prevents complement-enhanced activation of autoimmune human B cells in vitro. J Immunol 2019;202;1200-9.

[42] Shi J, Rose EL, Singh A, Hussain S, Stagliano NE, Parry GC, et al. TNT003, an inhibitor of the serine protease C1s, prevents complement activation induced by cold agglutinins. Blood $2014 ; 123 ; 4015-22$.

[43] Wahrmann M, Mühlbacher J, Marinova L, Regele H, Huttary $\mathrm{N}$, Eskandary F, et al. Effect of the anti-C1s humanized antibody TNT 009 and its parental mouse variant TNT 003 on HLA antibody-induced complement activation-a preclinical in vitro study. Am J Transplant 2017;17;2300-11. 